\title{
Inclusão Escolar de Crianças com Deficiência Múltipla: Concepções de Pais e Professores ${ }^{1}$
}

\author{
Flávia Furtado Silveira \\ Marisa Maria Brito da Justa Neves ${ }^{2}$ \\ Universidade de Brasília
}

\begin{abstract}
RESUMO - O presente trabalho teve como objetivo identificar as concepções dos pais e dos professores de crianças com deficiência múltipla sobre a inclusão escolar e social dessas crianças. Participaram deste estudo 10 famílias (sete casais e três mães) e 10 professoras de crianças deficientes múltiplas, atendidas pelo Programa de Atendimento a Deficientes Múltiplos da Secretaria do Estado de Educação do Distrito Federal. Utilizaram-se entrevistas semi-estruturadas com os pais e os professores e observações no ambiente escolar. Os resultados indicaram que os pais percebem a deficiência do filho como algo que acarreta grande sofrimento e que traz comprometimentos sociais, principalmente relacionados ao trabalho. Os pais e os professores acreditam não ser possível a inclusão escolar dessas crianças, por conceberem o desenvolvimento delas como inexistente e por considerarem a escola de ensino regular despreparada para recebê-las.
\end{abstract}

Palavras-chave: deficiência múltipla; concepções de pais e professores; inclusão escolar e social.

\section{Scholar Inclusion of Multiple Deficiency Children: Parents and Teachers Conceptions}

\begin{abstract}
This research aimed at identifying the conceptions of parents and teachers of children with multiple deficiencies, regarding their scholar and social inclusion. Ten families (seven couples and three mothers) as well as 10 teachers of multiple deficiency children participated in this research; these children are attended by the Program of Attendance to Multiple Deficient of the State Secretary of Education of the Federal District - SEDF. Half-structured interviews were made with parents and teachers and also observation of the scholar environment. The results indicated that parents are aware of their children's deficiency as something that brings great suffering and social limitations, specially related to work. Parents and teachers believe that the scholar inclusion of these children is not possible, for conceiving their development as inexistent and for considering the regular teaching school unprepared to receive them.
\end{abstract}

Key words: multiple deficiencies; conceptions of parents and teachers; scholar and social inclusion.

A inclusão escolar da pessoa com necessidades educacionais especiais é um tema de grande relevância e vem ganhando espaço cada vez maior em debates e discussões que explicitam a necessidade de a escola atender às diferenças intrínsecas à condição humana.

A Declaração Mundial sobre Educação para Todos (Unesco, 1990), aprovada pela Conferência Mundial sobre Educação para Todos, realizada em Jomtiem - Tailândia, no ano de 1990, e a Declaração de Salamanca (Unesco, 1994), firmada na Espanha em 1994, marcam, no plano internacional, momentos históricos em prol da Educação Inclusiva. No Brasil, a Constituição Federal de 1988, art. 208, inciso III (Brasil, 1988), o Plano Decenal de Educação para todos, 1993 - 2003 (MEC, 1993) e os Parâmetros Curriculares Nacionais (MEC, 1999) são exemplos de documentos que defendem e asseguram o direito de todos à educação. Segundo esses

1 Este trabalho é parte da Dissertação de Mestrado da primeira autora, apresentado no Instituto de Psicologia da Universidade de Brasília, sob a orientação da segunda autora.

2 Endereço: Universidade de Brasília, Instituto de Psicologia, Departamento de Psicologia Escolar e do Desenvolvimento, Campus Universitário Darcy Ribeiro, Brasília, DF, Brasil 70919-900. E-mail: marisa. brito.neves@uol.com.br documentos, todas as crianças devem ser acolhidas pela escola, independente de suas condições físicas, intelectuais, sociais, emocionais.

A inclusão escolar do deficiente múltiplo - pessoas com duas ou mais deficiências de base associada - que, na maioria das vezes, é percebido como o educando com necessidades educacionais "mais acentuadas", é fato bastante recente na educação brasileira (MEC, 2002). Nos questionamentos sobre a possibilidade de inclusão escolar dessa população, ainda habitam no imaginário social e individual dos profissionais da educação e dos familiares dessas crianças, desconhecimento e dúvidas que culminam em incertezas sobre os benefícios e as possibilidades da inclusão.

É consenso que a pessoa com necessidades educacionais especiais se beneficia das interações sociais e da cultura na qual está inserida, sendo que essas interações, se desenvolvidas de maneira adequada, serão propulsoras de mediações e conflitos necessários ao desenvolvimento pleno do indivíduo e à construção dos processos mentais superiores (Vygotsky, 1987).

Para Vygotsky, a transformação dos processos mentais elementares em funções superiores ocorre por meio das atividades mediadas e por meio das ferramentas psicológicas, o que implica, para esse autor, que a formação da subjeti- 
vidade individual decorre do relacionamento com os outros (Gindis, 1995).

As proposições de Vygotsky (1993) na área da Defectologia conduziram o autor a propor que o desenvolvimento de uma criança deficiente representa, sempre, um processo criativo e que essa criança apresenta meios particulares de processar o mundo. A abordagem de Vygotsky incorpora a noção de compensação e, de acordo com o autor, no contato do indivíduo deficiente com o mundo externo surgem conflitos, e a resolução desses conflitos pode propiciar a emergência de soluções alternativas, que se constituem em formas qualitativamente diferentes das funções psicológicas superiores. Desta maneira, Vygotsky assume uma posição que privilegia a importância dada à aprendizagem escolar como promotora do desenvolvimento e que reconhece o papel desempenhado pelo professor como mediador no processo de aquisição de conhecimento, na formação de conceitos científicos e no desenvolvimento cognitivo de seus alunos.

Ao compreender o desenvolvimento como um processo qualitativamente diferente para cada indivíduo, no qual os obstáculos podem ser contornados por meio de processos compensatórios, sendo a mediação fundamental para a obtenção de bons resultados, as proposições de Vygotsky sobre o desenvolvimento anormal oferecem uma visão da deficiência como uma anormalidade social e as diferenças no desenvolvimento passam a ser vistas como variações qualitativas.

Páez (2001) descreve que a inclusão pode trazer benefícios incontestáveis para o desenvolvimento da pessoa com deficiências, desde que seja oferecido na escola regular, necessariamente, uma Educação Especial que, em um sentido mais amplo, "significa educar, sustentar, acompanhar, deixar marcas, orientar, conduzir" (p. 33).

Desta forma, a inclusão escolar pressupõe mudanças físicas relacionadas a posturas frente às concepções que co-habitam na escola, sendo que um dos embates de maior significância é o que se refere à formação de professores em níveis teóricos, práticos e pessoais, que, na maioria das vezes, se mostra bastante insólita para edificar práticas que realmente estimulem a autonomia, a criatividade e a ampliação das competências do aluno com deficiência múltipla. Para Esteban (1989), "a concepção que o professor tem de mundo e de homem tem relação com sua concepção sobre o processo de alfabetização, assim como a leitura que faz do desenvolvimento da criança tem relação com a qualidade da sua intervenção" (p. 77).

Também se revestem de grande importância as concepções e expectativas dos familiares em relação à pessoa com necessidades educacionais especiais. Para Jerusalinsky e Páez (2001), as concepções e expectativas familiares proporcionarão um arsenal simbólico que muito dirá sobre como essa criança deverá ser incluída no ambiente social. No entanto, para que essa inclusão aconteça de maneira efetiva, é preciso mostrar à criança as representações e os traços privilegiados pelo discurso social para possibilitar que ela possa vir a representar-se nesse discurso.

Estudos que abordam as relações familiares de crianças com problemas no desenvolvimento apontam um alto nível de estresse nos pais, em especial nas mães, de crianças com deficiências e uma maior tendência desses pais em desen- volverem depressão (Glidden \& Floyd; Negrin \& Cristante, citados por Dessen \& Silva, 2000).

Por se reconhecer a importância da escola e da família no desenvolvimento das crianças com deficiência múltipla, justifica-se a relevância do presente trabalho. As concepções das pessoas envolvidas no cotidiano dos deficientes múltiplos nos permitem entender a natureza e a qualidade de suas intervenções, considerando que as ações são orientadas pelas concepções historicamente construídas (Oliveira, 1999).

Decorre destes pressupostos, a formulação desse estudo que teve como objetivo geral investigar as concepções dos pais e dos professores de crianças com deficiência múltipla sobre a inclusão escolar e social dessas crianças.

\section{Método}

\section{Contextualização da pesquisa}

O presente estudo foi realizado com pais e professores de crianças com deficiências múltiplas que freqüentavam, no ano de 2003, as classes para deficientes múltiplos de dois Centros de Ensino Especial do Distrito Federal. De cada centro, participaram os pais e os professores de cinco crianças, totalizando 10 famílias e 10 professores. As 10 crianças tinham, na época do estudo, idade entre 4 e 10 anos, sendo cinco crianças do sexo feminino e cinco do sexo masculino.

Dentre as deficiências de base associadas, sete crianças eram acometidas por deficiências física e mental; duas, por deficiências física, mental e visual; e uma por deficiências física, auditiva e mental. Tais dificuldades, nessas crianças, são decorrentes de diagnóstico de hidrocefalia (quatro crianças), e de outras intercorrências tais como: síndrome de West, microcefalia, paralisia cerebral por sofrimento fetal, entre outros diagnósticos.

\section{Participantes}

Pais - Participaram deste estudo 10 famílias (sete casais e três mães) de crianças com deficiências múltiplas. Os pais tinham idade entre 23 e 44 anos e as mães idades entre 25 e 43 anos. Os pais apresentavam as ocupações de pedreiro, balconista e serviços gerais. Das 10 mães, nove se dedicavam aos afazeres domésticos, e uma era psicóloga atuando em uma instituição pública.

Professores - Participaram 10 professores das crianças. Os professores em sua maioria (nove) eram do sexo feminino. Quanto ao tempo de trabalho no Ensino Especial, oito professores tinham tempo de atuação igual ou inferior a cinco anos, e dois, atuavam no Ensino Especial por um período entre seis e 11 anos.

\section{Instrumentos}

Utilizaram-se com os pais duas entrevistas semi-estruturadas. A primeira entrevista (Anexo 1) teve como objetivo principal levantar as concepções dos pais sobre a inclusão escolar e social dos seus filhos. A segunda entrevista (Anexo 2) foi realizada com o auxílio de fotografias, com intuito de demonstrar a forma como essas famílias desenvolvem, na vida diária, a socialização e a inclusão social dessas crianças. 
Era pedido que os pais apresentassem a criança, por meio das fotografias, à pesquisadora.

Com os professores, realizou-se uma entrevista semiestruturada (Anexo 3), com o objetivo de verificar suas concepções a respeito da inclusão escolar e social dos alunos com deficiência múltipla. Com o intuito de verificar o modo como se processam as práticas dos professores e poder relacioná-las às suas concepções, foram realizadas observações no contexto escolar, utilizando-se uma versão modificada (Anexo 4) do modelo apresentado por Bassedas e cols. (1996).

\section{Construção e análise dos dados}

Inicialmente foi solicitada à Secretaria de Estado de Educação do Distrito Federal a autorização para realização da pesquisa. De posse da autorização, uma das pesquisadoras dirigiu-se aos Centros de Ensino Especial e explicou os objetivos da pesquisa aos diretores e professores. A escolha dos participantes foi determinada pela possibilidade de aceitação do professor e das famílias das crianças, respeitando-se o limite de cinco crianças de cada Centro. Tanto os professores, como os pais, foram esclarecidos sobre os objetivos da pesquisa, aceitaram e autorizaram, por escrito, participar de sua realização.

A coleta dos dados com os pais ocorreu no período de junho a agosto de 2003 , tendo a primeira entrevista a duração média de uma hora e as entrevistas com apoio de fotografias a duração média de uma hora e 30 minutos. As entrevistas com os professores foram realizadas nos meses de agosto e setembro de 2003 e tiveram a duração de 50 minutos. As observações das atividades desenvolvidas pelos professores com seus alunos ocorreram nesse mesmo período, e tiveram a duração de uma hora e 15 minutos. Essas observações ocorreram em sala de aula, no pátio e no refeitório.

Todas as entrevistas foram gravadas em áudio e transcritas na íntegra. Após a transcrição das entrevistas, os dados foram submetidos à análise de conteúdo, conforme proposta de Bardin (1977). A análise de conteúdo aplica-se a discursos e baseia-se na dedução ou inferência sistemáticas, de forma objetiva identificando algumas características da mensagem, por meio da construção de categorias, reunidas por temas de significação (Berg, 1998; Bauer, 2002).

\section{Resultados e Discussão}

Apresentam-se a seguir, e separadamente, os resultados e a discussão dos dados obtidos com os pais e com os professores e, depois, as semelhanças encontradas entre as concepções dos pais e as dos professores.

\section{Concepções dos pais}

A análise das primeiras entrevistas realizadas com os pais, que tiveram como objetivo levantar suas concepções sobre a inclusão escolar e social, possibilitou o levantamento de quatro categorias, agrupadas por temas de significação semelhantes, dispostos a seguir (Quadro 1).

Em relação à primeira categoria - Impacto do diagnóstico na vida familiar - os pais relataram terem vivenciado

Quadro 1. Categorias das concepções dos pais sobre a inclusão escolar e social do deficiente múltiplo $(N=10)$.

\begin{tabular}{ll}
\hline Categorias & \multicolumn{1}{c}{ Definição } \\
\hline Impacto do diagnóstico & $\begin{array}{l}\text { Os pais descreveram os sentimentos iniciais } \\
\text { na vida familiar }\end{array}$ \\
& gústia, susto, medo, insegurança), passando \\
& pelo momento de adaptação, onde puderam \\
& vislumbrar possibilidades futuras. Têm dificul- \\
& dades para entender o diagnóstico, que trouxe \\
& mudanças como: alteração na produtividade do \\
& trabalho, na vida religiosa e no lazer.
\end{tabular}
Aprendizagem e
inclusão

Impacto da deficiência na educação e socialização
Os pais desacreditam na possibilidade de inclusão escolar, por dificuldades da escola de ensino regular e do próprio deficiente múltiplo. Quanto à escola especial, ela necessita de mudanças relacionadas à disponibilização de profissionais da saúde, como médicos, fonoaudiólogos e fisioterapeutas, para atenderem às crianças em suas dificuldades.

Os pais, principalmente as mães, se referiram à grande dificuldade em estabelecer limites à criança deficiente múltiplo. Há um comprometimento em relação ao lazer, restringido praticamente em ir para a escola, devido às dificuldades de como a criança não ter controle de esfíncter, não dormir e/ou não comer fora de casa, além de não gostar de ambientes tumultuados e de ter dificuldades de deixar a criança com outra pessoa.

Direitos e desrespeito Referiram-se, principalmente, ao direito ao à pessoa com necessidades educacionais especiais transporte coletivo que, na maioria das vezes, é desrespeitado pelos motoristas e pelos passageiros dos ônibus.

Outras dificuldades descritas foram: habitação própria adaptada e próxima ao Centro de Ensino Especial; necessidade de cadeiras de roda e discriminação por parte da sociedade.

momentos iniciais de bastante angústia, intensificada nos momentos posteriores, principalmente em quadros decorrentes de convulsão dos filhos.

Os pais têm dificuldade de encontrar uma explicação para o diagnóstico e, diante da inexistência de explicação pela equipe de saúde, preenchem o espaço vazio deixado pela falta de etiologia com explicações baseadas no senso-comum. Respostas do tipo: "o cérebro da criança havia cozinhado" ou algo que "somente a Deus caberia uma explicação".

Em relação às mudanças familiares, essas estão relacionadas principalmente ao emprego; em especial, ao emprego da mãe. A literatura aponta que as mudanças, inevitáveis diante do nascimento de um filho, particularmente de um filho com necessidades educacionais especiais, podem ser percebidas, como foi encontrado nas respostas dos pais, de forma positiva ou negativa. Pode haver casos em que alguns relacionamentos são fortalecidos e em outros casos, essa relação pode ser de intenso sofrimento, no qual um dos pais sofre de maneira isolada e a seu modo a situação (Miller, 2002).

A segunda categoria - Aprendizagem e inclusão - aponta que os pais acreditam ser o ensino especial a melhor opção para suas crianças, considerando as extremas dificuldades apresentadas por seus filhos. Consideram muito difícil a 
possibilidade de seus filhos estarem inseridos em classes regulares. Apontaram as turmas cheias, o despreparo dos professores, o preconceito por parte dos alunos e, mais uma vez, as dificuldades exacerbadas da própria criança, como os principais fatores impeditivos da inclusão.

Os dados desta pesquisa, em consonância com Kassar (1999), demonstram que, para os pais, a escola tem seu valor para os deficientes múltiplos somente no sentido da interação com outros colegas em detrimento da aprendizagem sistemática.

A terceira categoria - Impacto da deficiência na educação e socialização - sumarizou respostas nas quais os pais demonstraram grande dificuldade em empreender ações educacionais estabelecendo limites e promovendo a autonomia de suas crianças. Alguns pais verbalizaram que, para eles, a criança seria sempre um bebê. Nessa mesma direção, Kassar (1999) apontou a tendência que as famílias têm de perceber as crianças gravemente comprometidas de forma infantilizada, por toda a vida.

Em relação à socialização, as respostas de nove pais foram unânimes em apontar que as dificuldades da criança em relação à higienização, ao humor, à alimentação, dentre outras, constituem-se em fatores dificultadores do lazer familiar.

A categoria - Direitos e desrespeito à pessoa com necessidades educacionais especiais - indica que as respostas dos pais apontaram que o descumprimento desses direitos afeta diretamente a família e a criança. Para Silva (2001), o impacto da deficiência/pobreza alcança dimensões bastante negativas, principalmente ao gerar espaço para que ações assistencialistas se proliferem.

Os pais deste estudo, usuários do transporte coletivo, relataram comportamentos de impaciência dos motoristas e atitudes de intolerância e desrespeito por parte dos passageiros. Esses relatos apontam para o despreparo da população em relação ao convívio e aos direitos das pessoas com necessidades educacionais especiais em termos dos assentos preferenciais.

A segunda entrevista realizada com os pais contou com o apoio de fotografias. Penn (2002), ao ressaltar a importância da análise de imagens para o campo científico, denota a importância de uma leitura que se apóie em informações adicionais para além do que está registrado em fotografias. Assim, "cada imagem contém um contexto e sentidos próprios que só poderiam ser atingidos, ou melhor, construídos se as fotos falassem. Por isso, imagem e narrativa formam um par harmonioso que, juntas, construirão significados" (Caixeta, 2001, p. 49). Neste sentido, as fotografias são, antes de tudo, instrumentos que potencializarão lembranças, que poderão fornecer pistas sobre as concepções dos pais e as dos professores a respeito da criança deficiente múltipla.

Em relação às fotografias, elas retratavam, em sua maioria, cenas familiares, seja com a criança em casa sozinha ou com irmãos ou primos. No caso de diagnóstico precoce, as primeiras fotos foram acompanhadas de verbalizações que indicavam sofrimento e angústia em relação ao problema da criança, sendo que algumas fotos foram tiradas ainda no hospital ou em internações posteriores. Das crianças que foram diagnosticadas posteriormente, as primeiras fotos sempre foram indicadas como momentos felizes vivenciados, na medida em que ainda não lidavam com o problema do filho.
A maioria das famílias apresentou pelo menos uma foto de passeio, apesar de esses se restringirem à visita a casa e ao sítio de parentes ou à Igreja. Em relação a festas, a maioria das fotos foi tirada em festas na escola, o que confirma o discurso dos pais ao relatarem que a escola é o espaço prioritário de lazer das crianças. Metade das famílias apresentou fotografias de festas de aniversário das crianças. Dentre os pais que relataram não comemorarem os aniversários, foram encontrados aqueles que entendiam ser isso desnecessário, devido ao fato de a criança não compreender o que estava se passando.

Quando se pediu aos pais que escolhessem uma foto que melhor representasse a criança, os pais escolheram sempre fotos alegres. Algumas fotos foram anteriores ao diagnóstico e, as fotos tiradas após o diagnóstico, foram com familiares ou, ainda, fotos que segundo os pais, a deficiência não ficava tão notória.

A análise dos dados gerados na segunda entrevista com os pais apontou grandes similaridades com os conteúdos da primeira entrevista que tratou de suas concepções. Os temas de significação não apresentaram contradições entre as concepções e as práticas realizadas. Para os pais, a inclusão escolar e social de seus filhos é determinada por concepções baseadas em visões medicalizadas e biológicas que dificultam o desenvolvimento de práticas que promovam a aprendizagem e o desenvolvimento.

\section{Concepções dos professores}

A análise das entrevistas realizadas com os professores levantou dados sobre suas concepções a respeito da inclusão escolar e social dos alunos com deficiências múltiplas e possibilitou o levantamento de quatro categorias, agrupadas por temas de significação. Essas categorias estão demonstradas no Quadro 2.

Na primeira categoria - Critérios para a inclusão - os professores argumentam que a inclusão só é possível para pessoas com necessidades educacionais especiais menos comprometidas, demonstrando uma descrença em relação à inclusão escolar do deficiente múltiplo. Esse dado diverge do que é exposto pelo MEC (2002), quando afirma que a grande maioria dessas crianças adapta-se muito bem à educação regular, com a convivência, o envolvimento de profissionais especializados e o comprometimento da família.

Outros fatores que impossibilitam a inclusão dos deficientes múltiplos, para esses participantes, seriam as condições insalubres da escola de ensino regular, como a falta de preparo dos professores. Concorda-se com Carvalho (2001), quanto à afirmação de que o discurso do despreparo técnico e prático apenas cristaliza e imobiliza as ações inclusivas.

A segunda categoria - Impacto da deficiência nas atividades - reflete o descrédito no desenvolvimento e aprendizagem e, conseqüentemente, na capacidade dos deficientes múltiplos executarem atividades que denotam autonomia e exigem reflexão, abstração e memória.

Quando indagados sobre os objetivos educacionais, os professores demonstraram dificuldades em defini-los. Os professores não definem as atividades de socialização, de autonomia em relação à higiene pessoal, como atividades de cunho pedagógico. Dessa forma, consideram impossível 
Quadro 2. Categorias das concepções dos professores sobre a inclusão escolar e social do deficiente múltiplo $(N=10)$.

\begin{tabular}{ll}
\hline Categorias & \multicolumn{1}{c}{ Descrição } \\
\hline Critérios para a & A inclusão só pode ser possível se for realizada \\
inclusão & com cautela e em longo prazo, se levar em \\
& conta o comprometimento da criança, se não \\
& se destinar aos mais comprometidos, se for so- \\
mente no campo social e se houver um preparo & do corpo técnico e do ambiente físico.
\end{tabular}

Impacto da deficiência Descrevem como principal objetivo, nas nas atividades

\section{Atendimento individualizado para o deficiente múltiplo} atividades desenvolvidas com seus alunos, a independência nas atividades de vida diária. Os professores relatam desenvolver papel de "babás", enfocando atividades de higienização, massagem, música, gestos e brincadeiras, sendo inviável o trabalho pedagógico.

Sentimentos de frustração são relatados, sendo amenizados por meio da conscientização da importância da sua presença e da afetividade para as crianças.

Os professores relatam a necessidade de atendimento especializado devido às dificuldades dos alunos (serem dependentes, apresentarem impossibilidade de desenvolvimento e de aprendizagem). Relatam, ainda, que os professores das escolas regulares não estão preparados, em termos práticos e técnicos, para atender à demanda. As salas dessas escolas são consideradas inadequadas para a permanência do deficiente múltiplo.

Relação família-escola e demandas familiares

Apesar das dificuldades, limitações financeiras, de transporte e as decorrentes da deficiência do filho; bem como do descrédito de alguns pais na importância da socialização da criança, a integração família-escola é considerada satisfatória. Acreditam que a continuação do trabalho em casa é primordial para o desenvolvimento do filho. Descrevem a necessidade de uma rede de apoio aos pais, pois eles têm muitas dificuldades diante da situação do filho.

a realização de qualquer atividade pedagógica com os deficientes múltiplos. Os professores parecem considerar apenas as atividades de letramento e aquisições matemáticas como atividades pedagógicas. Essas concepções induzem o desenvolvimento das demais atividades de forma espontaneísta e não intencional.

A maioria dos professores relatou experienciar sentimentos de frustração em relação ao atendimento à criança, mas, a fim de resolverem os conflitos emergentes desses sentimentos, acreditam que só a afetividade que dispensam às crianças já é o bastante.

Em relação a esta questão, os dados encontrados nesta pesquisa seguem na mesma direção da literatura. Há uma tendência em se considerar a pessoa com necessidades educacionais especiais tendo baixas perspectivas de aprendizagem, de escolarização e com total nível de dependência por toda a vida (Carvalho, 2001).

A análise da terceira categoria - Atendimento individualizado para o deficiente múltiplo - apontou que os professores consideram o ensino regular como um espaço que não propicia o desenvolvimento concomitante de atividades com os alunos regulares e com os deficientes múltiplos. Eles consideram a dependência de cuidados práticos, tais como dar banho, trocar fraldas, como um fator de forte impedimento ao trabalho do professor.

Em relação a esta constatação, Kruppa (2001) assegura que "a escola não acredita na capacidade de aprender de todo ser humano e se julga competente para apontar de forma arbitrária, preconceituosa e equivocada aqueles que 'podem' aprender' (p. 28).

Por desacreditarem no desenvolvimento dos alunos, alguns professores profetizaram que algumas crianças iriam passar a vida no atendimento aos deficientes múltiplos.

A última categoria levantada - Relação família-escola $e$ demandas familiares - apresentou dados que indicam o reconhecimento por parte dos professores da importância do trabalho conjunto com as famílias. Segundo os professores, há pais omissos, que transferem a responsabilidade aos professores e outros bastante ansiosos. Diante destes últimos, só resta aos professores, vista as altas expectativas de alguns, omitir dados em relação ao que acreditam ser as verdadeiras potencialidades do aluno.

Os professores desta amostra relataram o predomínio de bom relacionamento entre família e escola e evidenciaram a necessidade de um trabalho conjunto, a fim de atender aos deficientes múltiplos em suas dificuldades. Ao mesmo tempo, encontram-se nos discursos dos professores algumas questões que "arranham" a confiança e a franqueza na relação, o que dificulta, sobremaneira, uma interação pais-escola alicerçada, sobretudo, no respeito mútuo, apesar de os professores reconhecerem as dores e as dificuldades dos pais de crianças com necessidades educacionais especiais.

A análise das observações das práticas desenvolvidas pelos professores assinalou pistas importantes sobre como as concepções dos professores se concretizam em suas práticas pedagógicas. Porém, verifica-se a necessidade de um estudo mais aprofundado sobre as práticas pedagógicas dos professores das escolas especiais.

Contudo, de maneira exploratória, os dados dessa observação corroboraram com os conteúdos das entrevistas, na medida em que parece que os professores, em sua grande maioria, estruturam suas atividades tendo como base as crenças recorrentes da incapacidade no desenvolvimento e na aprendizagem do deficiente múltiplo. Às crianças, em muitos momentos, não eram dispensadas as mediações para uma atividade ou, passavam muito tempo sem uma atividade direcionada, enquanto os professores conversavam entre si. A falta de planejamento das atividades a serem desenvolvidas com as crianças foi recorrente nas observações realizadas.

\section{Concepções de pais e professores: semelhanças e diferenças}

As concepções dos pais e as dos professores sobre a inclusão escolar e social e, também, sobre as possibilidades de desenvolvimento e aprendizagem dos alunos com deficiências múltiplas, apesar de suas especificidades, apresentaram-se, em sua grande maioria, convergentes.

Sobre a inclusão escolar - Pais e professores concordam em relação à impossibilidade de se realizar a inclusão escolar do deficiente múltiplo, principalmente por acreditarem que 
suas dificuldades, as da escola de ensino regular e as das crianças que dela fazem parte, inviabilizariam o processo de inclusão escolar.

Sobre inclusão social - Ambos acreditam na importância das interações sociais para o desenvolvimento do deficiente múltiplo e, inclusive, percebem a inclusão social como a única viável, pois não acreditam na possibilidade de inclusão escolar dessas crianças.

Sobre o desenvolvimento dos deficientes múltiplos - As concepções dos pais e as dos professores deste estudo parecem convergir, quando se trata das características do desenvolvimento do deficiente múltiplo. A deficiência, principalmente para os professores, tem caráter estritamente biológico e, portanto, diante das dificuldades, esses alunos estariam fadados a se desenvolver de maneira lenta e imperceptível.

Sobre as possibilidades de aprendizagem - Pais e professores reconhecem alguns progressos alcançados pela criança, principalmente aqueles relacionados à autonomia em atividades práticas cotidianas e a socialização, porém, embasados em concepções idealizadas, centram-se nas limitações das crianças.

Percepções e sentimentos frente à deficiência - Os pais e os professores se relacionam com a deficiência das crianças de modo estanque. Antecipam resultados de fracassos e de decepções. No entanto, os pais mostraram perspectivas futuras mais positivas e mais esperançosas que os professores.

\section{Considerações Finais}

As concepções dos pais e as dos professores problematizam a dificuldade da inclusão escolar dos deficientes múltiplos, principalmente no que se refere a dificuldades de esses alunos acompanharem os conteúdos ministrados na sala de ensino regular.

De acordo com os dados deste estudo, o olhar inclusivo sobre as escolas especiais ou regulares, deve ser um olhar de mudanças e inquietações, que vem assinalar a necessidade de transformações no sistema educacional, no sentido de considerar as pessoas, suas histórias, concepções, percepções, crenças, experiências e trajetórias pessoais. Tanto os pais, que em sua maioria advêm de um nível sócio-econômico desfavorecido extremamente desrespeitados em seus direitos, quanto os professores, apresentaram em seus discursos severo descrédito no desenvolvimento e na aprendizagem dos deficientes múltiplos.

Neste sentido, a formação profissional passa a ser uma questão central para a implantação da escola inclusiva. Acima de tudo, a predisposição para perceber o aluno como ser cognocente e se perceber como peça-importante no desenvolvimento do aluno, de forma a co-responsabilizar-se pelas mudanças que urgem serem realizadas no processo educacional, se traduz como uma questão urgente a ser enfrentada no trabalho com os professores.

Portanto, garantir um espaço de informação/formação/redefinição poderia colaborar no sentido de promover debates sobre os fatores referentes às baixas expectativas dos pais e professores em relação ao desenvolvimento e à aprendizagem dos deficientes múltiplos, articulando-os para cobrarem de todo o sistema educacional posturas e práticas de qualidade.
A escola deve estar aberta, em todo momento, à participação dos pais dessas crianças, inclusive no que se refere à presença em determinadas aulas, para que esteja claro, para os pais, a seriedade da proposta pedagógica específica para seu filho, bem como para que se possa instrumentalizar os pais para atividades possíveis de serem realizadas em casa.

Tratando-se das políticas públicas, a partir dos discursos de pais e professores, a respeito das situações em que experienciaram o desrespeito aos seus direitos, evidenciou-se a necessidade de realização de políticas públicas, destinadas à população em geral, a respeito da necessidade de todos terem ações de tolerância à diversidade humana. Sabe-se, que as ações dos profissionais que lidam com o público é, também, função de políticas internas das instituições.

Ainda com relação às políticas públicas, elas hão que propiciar maior investimento em materiais pedagógicos, próteses e órteses e recursos de adaptação para as escolas inclusivas, a fim de se garantir meios que facilitem a acomodação, comunicação e aprendizagem dos alunos com necessidades educacionais especiais, assim como se deve questionar a eficácia dos treinamentos e cursos destinados aos professores que lidam com esses alunos.

Desta forma, a inclusão remete à urgência da transformação de toda a realidade social e escolar. À escola, preconizam-se as mudanças relacionadas ao acolhimento do sujeito como ser em constante construção e desenvolvimento. O conhecimento deve, outrossim, ser percebido não como algo determinado e acabado, mas como o produto da co-construção gerado pela interação entre o indivíduo, o meio físico e as relações humanas. Portanto, isso significa a reflexão sobre as concepções que permeiam as construções cognitivas de pais, de professores e de todos os agentes da escola, que culminem em práticas em que a prioridade seja dada à mediação do outro, em se tratando da disponibilização dos bens culturais à participação do deficiente múltiplo.

\section{Referências}

Bardin, L. (1977). Análise de conteúdo. Lisboa: Edições 70.

Bassedas, E.; Huguet, T.; Marrodán, M.; Oliván, M.; Planas, M.; Rossell, M.; Seguer, M. \& Vilella, M. (1996). Intervenção educativa e diagnóstico psicopedagógico. (B. A., Neves, Trad.). Porto Alegre: Artes Médicas. (Trabalho original publicado em 1993).

Bauer, W. M. (2002). Análise de conteúdo clássica: uma revisão. Em M. W. Bauer \& G. Gaskell (Orgs), Pesquisa qualitativa com texto, imagem e som - um manual prático (pp. 189-217, A. P. Guareschi, Trad). Petrópolis: Vozes. (Trabalho original publicado em 2000).

Berg, B. L. (1998). Qualitative research methods for the social sciences. Boston: Allyn and Bacon.

BRASIL.(1988). Constituição da República Federativa do Brasil. São Paulo: Encyclopaedia Britannica do Brasil.

Caixeta, J. E. (2001). A mulher em envelhecimento no seu cotidiano: diálogos, textos e imagens sobre a identidade feminina. Dissertação de Mestrado, Universidade de Brasília, Brasília.

Carvalho, R. E. (2001). A incorporação das tecnologias na educação especial para a construção do conhecimento. Em S. Silva \& M. Vizim (Orgs.), Educação especial: múltiplas leituras e 
diferentes significados (pp. 57-84). Campinas: Mercado de Letras: Associação de Leitura do Brasil-ALB.

Dessen, M. A. \& Silva, N. L. P. (2000). Deficiência mental e família: uma análise da produção científica. Paidéia - Cadernos de Psicologia e Educação. 10(19), 12-23.

Esteban, M. T. (1989). Repensando o fracasso escolar. Caderno de Pesquisa-CEDES. 28, 73-86.

Gindis, B. (1995). The social/cultural implication of disability: Vygotsky's paradigm for special education. Educational Psychologist, 30(2), 77-81.

Jerusalinsky, N. A. \& Páez, S. M. C. (2001). Carta aberta aos pais acerca da escolarização das crianças com problemas de desenvolvimento. Escritos da criança, 6, 15-21.

Kassar, M. C. M. (1999). Deficiência múltipla e educação no Brasil-discurso e silêncio na história dos sujeitos. Campinas: Autores Associados.

Kruppa, S. M. P. (2001). As linguagens da cidadania. Em S. Silva, \& M. Vizim (Orgs.), Educação especial: múltiplas leituras e diferentes significados (pp. 13-39). Campinas: Mercado de Letras: Associação de Leitura do Brasil-ALB.

Miller, N. B. (2002). Ninguém é perfeito ( $3^{\mathrm{a}} \mathrm{ed}$.). Campinas: Papirus.

Ministério da Educação e Cultura (1993). Plano Decenal de Educação para Todos - 1993 a 2003. Brasília: MEC.

Ministério da Educação e Cultura. (1999). Parâmetros Curriculares Nacionais-Adaptações Curriculares, Estratégias para a Educação de Alunos com necessidades Educacionais Especiais. Brasília: MEC/SEE.

Ministério da Educação e Cultura (2002). Estratégias e orientações pedagógicas para a educação de crianças com necessidades educacionais especiais-Dificuldades acentuadas de aprendizagem. Deficiência múltipla. Brasília: MEC/SEE.
Oliveira, S. M. (1999). Valores e crenças de educadoras de creche sobre o desenvolvimento e educação de crianças de dois e três anos. Dissertação de Mestrado, Universidade de Brasília, Brasília.

Páez, S. M. C. (2001). A integração em processo: da exclusão à inclusão. Escritos da criança, 6, 29-39.

Penn, G. (2002). Análise semiótica de imagens paradas. Em M. W. Bauer \& G. Gaskell (Orgs), Pesquisa qualitativa com texto, imagem e som - Um manual prático (pp. 319-342, A. P. , Guareschi, Trad). Petrópolis: Vozes.

Silva, S. (2001). Educação especial - entre a técnica pedagógica e a política educacional. Em S. Silva \& M. Vizim (Orgs), Educação especial: múltiplas leituras e diferentes significados (pp. 179-171). Campinas: Mercado de Letras: Associação de Leitura do Brasil-ALB.

Unesco (1990). Declaração Mundial sobre Educação para Todos: Satisfação das Necessidades Básicas de Aprendizagem. Retirado em 15/07/2004, http://www.unesco.org.br/publicaçõe/ copy_of_pdf/decjomtien

Unesco (1994). Declaração de Salamanca e Linhas de Ação sobre Necessidades Educativas Especiais. Brasília: Corde.

Vygotsky, L. S (1987). Pensamento e linguagem. (J. L. Camargo, Trad.). São Paulo: Martins Fontes. (Trabalho original publicado em 1962)

Vygotsky, L. S. (1993). The fundamentals of defectology. Em R. W. Rieber \& A. S. Carton (Orgs.). The collected works of $L$. S. Vygotsky. vol. 2 (pp. 1-25). New York and London: Plenum Press. (Trabalho original publicado em 1925).

Recebido em 08.12.2005 Aceito em 12.04.2006

\section{NORMAS DE PUBLICAÇÃO}

São adaptadas de Publication Manual of the American Psy-

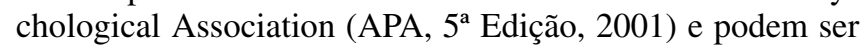
consultadas ao final de cada número (versão impressa ou online) ou no sítio: http://www.revistaptp.org.br 


\section{Anexo 1 - Primeira entrevista com os pais}

\section{I - Nascimento e diagnóstico da deficiência}

1. Como foi para vocês, para os irmãos e para demais familiares o nascimento de uma criança com necessidades educacionais especiais?

2. Por ocasião do nascimento, vocês procuraram ou receberam algum tipo de ajuda profissional? O que vocês entendem sobre o diagnóstico do seu filho e o que, para vocês, pode ter causado a deficiência?

3. Atualmente como vocês e os irmãos se relacionam com (nome da criança)?

\section{II - Dinâmica familiar}

1. Quem é ou quem são os responsáveis pelos cuidados com o/a (nome da criança)?

2. Relate um fato marcante da infância do/da (nome da criança)

3. Quais mudanças e/ou adaptações foram efetivadas na vida familiar após o nascimento da criança (nome da criança)?

4. Como é a educação do/da (nome da criança)? O que ela realiza de forma autônoma?

5. Como vocês imaginam o futuro do/da (nome da criança)?

\section{III - Atitudes e percepções frente à escolarização e socialização}

1. Como e de quem foi a iniciativa de levá-lo/la ao Centro de Ensino Especial? O que vocês pensam sobre a escolarização do/da (nome da criança)?

2. O que vocês pensam sobre a inclusão social e escolar da pessoa com necessidades educacionais especiais?

3. Como vocês avaliam a qualidade da escolarização do/da (nome da criança)?

4. O que vocês pensam que poderia mudar em relação à escolarização do/da (nome da criança)?

5. O que a família faz nos momentos de lazer?

6. O que vocês pensam a respeito da participação do (nome da criança) em atividades com outras crianças, como festas de aniversário e brincadeiras?

7. Fale algo sobre os direitos da pessoa com necessidades especiais.

8. Houve algum episódio em que vocês tiveram que cobrar, de algum membro da sociedade, uma postura diferenciada em relação à socialização, aceitação e escolarização do seu filho com necessidades educacionais especiais?

\section{Anexo 2 - Segunda entrevista com os pais}

\section{I - Introdução}

Mais uma vez eu convidei vocês para conversarmos sobre o/a (nome da criança), pois eu gostaria de saber um pouco mais sobre como vive o/a (nome da criança), o que ele/ela gosta de fazer, enfim, como é o seu dia-a-dia. Acredito que com as fotos em mãos será mais fácil lembrar sua trajetória de vida, seus primeiros anos, suas brincadeiras e os fatos marcantes de sua vida.

\section{II - História de vida}

Em primeiro lugar, gostaria que contassem sobre a vida do/da (nome da criança) utilizando os fatos registrados pelas fotografias.

Conte-me, por meio das fotos, a história de vida do/da (nome da criança).

1. Em que circunstâncias foram tiradas as primeiras fotos?

2. Vocês lembram o que sentiam na época dessa foto?

3. Vocês registraram algum momento do/da (nome da criança) em situação de brincadeira?

4. Eram oferecidos brinquedos para que brincasse? Que tipos de brinquedos?

5. Com que frequiência costumam passear? Onde e como são esses passeios? Há registros em fotos?

6. Qual a foto que melhor representa a vida do/da (nome da criança)?

\section{Anexo 3 - Roteiro de entrevista com professores}

1. Fale sobre o que você pensa da inclusão escolar e social da pessoa com necessidades educacionais especiais.

2. Faça considerações a respeito da inclusão escolar e social do deficiente múltiplo.

3. Relate as atividades desenvolvidas com os deficientes múltiplos.

4. Com os recursos disponíveis, como você pensa que poderia melhorar o atendimento a essas crianças?

5. Como tem se dado a interação família-escola? 